\title{
Iatrogenic Harlequin syndrome after thoracic spine surgery: a case report and literary review
}

\author{
Zeyad Abousabie ${ }^{1}$, Mohamed Almzeogi $^{2}$, aleksandar janicijevic ${ }^{3}$, Jelena Kostic ${ }^{1}$, and Goran \\ Tasic $^{3}$ \\ ${ }^{1}$ Klinicki centar Srbije \\ ${ }^{2}$ Univerzitetski klinički centar Srbije \\ ${ }^{3}$ klinicki centar srbije klinika za neurohirurgiju
}

July 4, 2021

\begin{abstract}
Here we present a unique case of Harlequin syndrome without Horner syndrome after contralateral Th3 intradural tumor resection. Harlequin sign in our case presented probably to resection of sympathetic nerves while removing meningioma. Syndrome is rare in neurosurgical procedure, but we think that surgeons must be aware of it.
\end{abstract}

Iatrogenic Harlequin syndrome after thoracic spine surgery: a case report and literary review

Kostic J , Abousabie.A.Zeyad, Almzeogi.A.Mohamed, Janicijevic.M.Aleksandar, Tasic.Goran

Clinic of Neurosurgery, Clinical center Serbia.

Zeyad Ali Salem Abousabie,.Email :ziad.znati@gmail.com, Mobile: +381 695218287

\section{Clinical message}

The Iatrogenic Harlequin syndrome is still a rare complication, especially in neurosurgical procedure but we think that the surgeons must be aware of this condition as a possible complication after the neurosurgical procedure.

\section{Background}

Case summary: 36 years old male with back pain with paresthesia of the right leg for over a one-year period. Magnetic resonance imaging (MRI) showed intraduralextramedullary tumor. Tumor resection was performed. Control magnetic resonance imaging (MRI) showed no signs of residual tumor, recurrence of tumor or signs of ischemia. Six months after the operation, the patient developed Harlequin syndrome with no Horner's syndrome.

Method: The PubMed database was searched online (PubMed, http:// pubmed.com). A search query using Harlequin syndrome revealed 129 published cases of which 23 was iatrogenic. Of 23 patients female sex was predominant $-15: 8$ ratio in which 8 were pediatric patients.

Objective: Harlequin syndrome in neurosurgical procedure is rare, but we think that the surgeons must be aware of this condition as a possible complication after the neurosurgical procedure.

Conclusion: Harlequin syndrome as a condition often frightens the patients since it happens after the operation, while they perform their usual activities. In most cases (about 80\%) it resolves by itself within 
few hours.

Keywords : Case report, harlequin syndrome, thoracic spinal cord, autonomic disorder.

\section{Introduction :}

Harlequin syndrome is still a rare, uncommon autonomic disorder caused by dysfunction of sympathetic innervation of the face. The symptoms that characterize it are unilateral loss of flushing of the face and neck and anhidrosis with compensatory flushing and sweating on the contralateral side. Horner's syndrome may be present. ${ }^{1}$

In most of the casesit is primarily idiopathic, but it can be associated with diabetic neuropathy, GuillianBarre syndrome, Bradbury-Eggleston syndrome, brain stem infarction,

superior mediastinal neurinoma and internal carotid artery dissection (secondary Harlequin syndrome) or as accidental injury to the sympathetic nervous system after invasive procedure - surgical procedures, central line insertion, or a peripheral nerve block (iatrogenic Harlequin syndrome) ${ }^{2,3,4}$, This syndrome may be transient or permanent..$^{5,6,7}$

To the best of our knowledge the syndrome has been associated with invasive procedures such as thoracotomy, cervical discectomy or paravertebral nerve block. Here we present a unique case of Harlequin syndrome without Horner syndrome after contralateral Th3 intradural tumor resection.

Case report:

36 years old male presented with the occasional back pain with paresthesia of the right leg for over a one-year period. Magnetic resonance imaging (MRI) showed intraduralextramedullary tumor, hyperintense mass on T1 - weighted contrast images, ventrolateral to the right in the level of Th3 corpus, dimensions $1.7 \mathrm{~mm} \mathrm{x}$ $1 \mathrm{~mm}$ (figure 1).

Neurological examination on admission was entirely normal, without any neurological deficit, without sensory level. The decision was made to proceed with the resection of the tumor.

Right sided hemilaminectomy was performed at the level of Th3. After the initial exposure of the tumor, which was solid, adherent to adjacent nerves, the tumor was totally resected. No intraoperative complications were noted.After the operation patient recovered well, without any neurological deficit. Subsequent histological analysis revealed that the tumor was transitional meningioma WHO grade I.

The patient was doing well, he returned to his regular activities. Six months after the operation, during the exercise the patient developed left side facial flushing, following sweating on the left side of the torso and face. Neurological examination was normal; there were neither Horner's syndrome nor any history of this occurring previously. No other symptoms were evident.(figure 2 was provided by patient).Control magnetic resonance imaging (MRI) showed no signs of residual tumor, recurrence of tumor or signs of ischemia (figure 3 and 4). On follow-up there was no recurrence of Harlequin syndrome. 

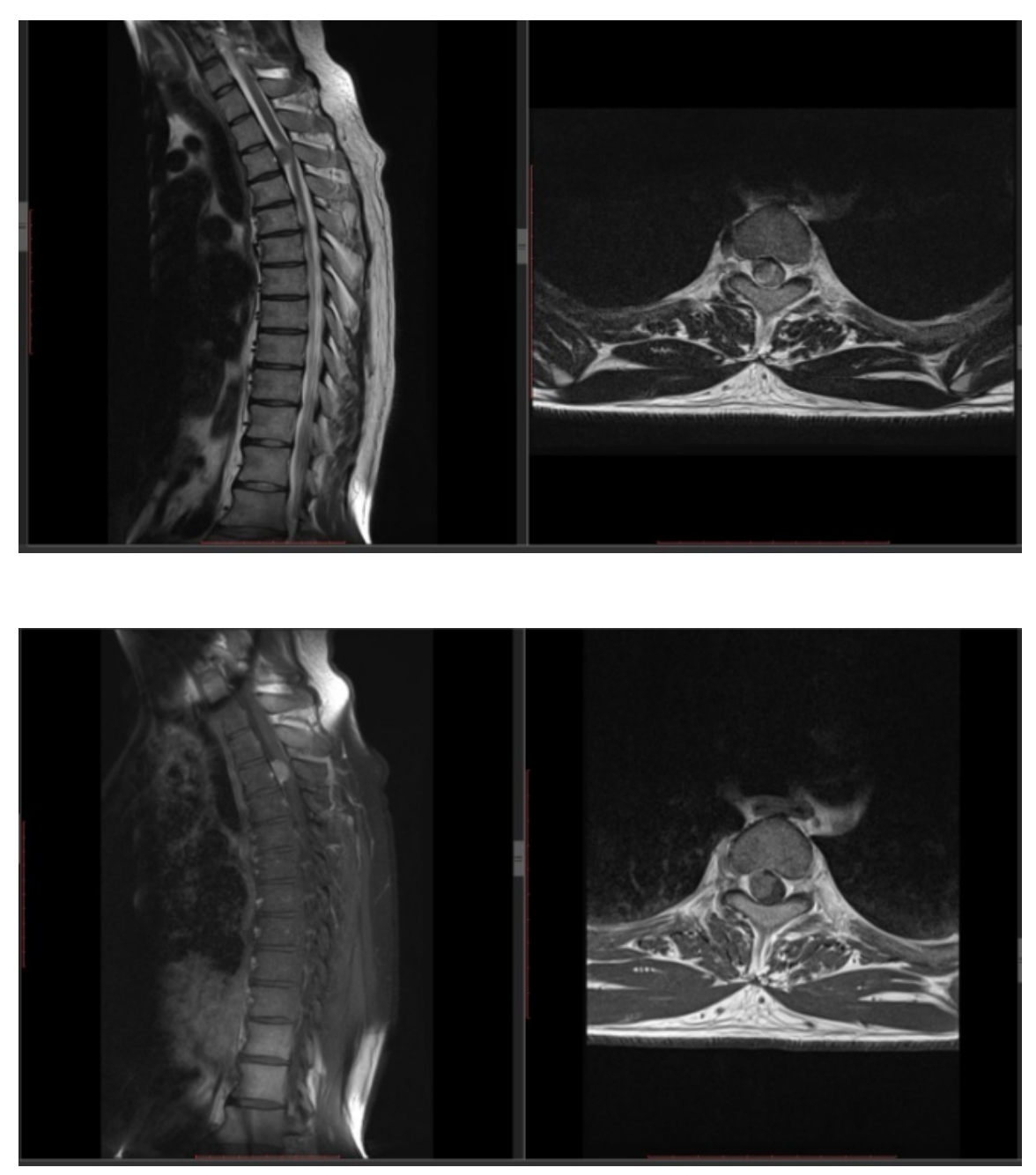

Figure 1(preoperative MRI) 


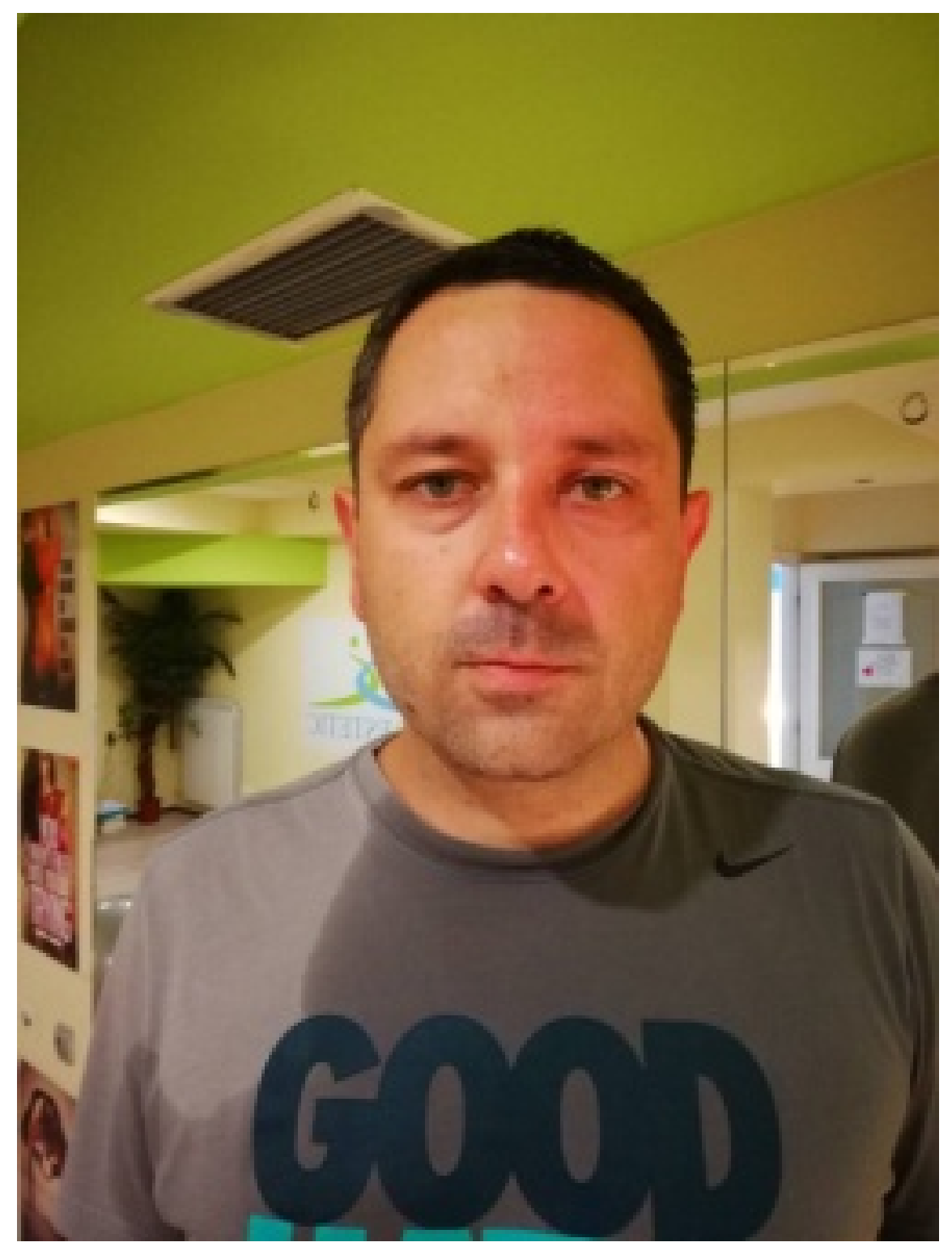




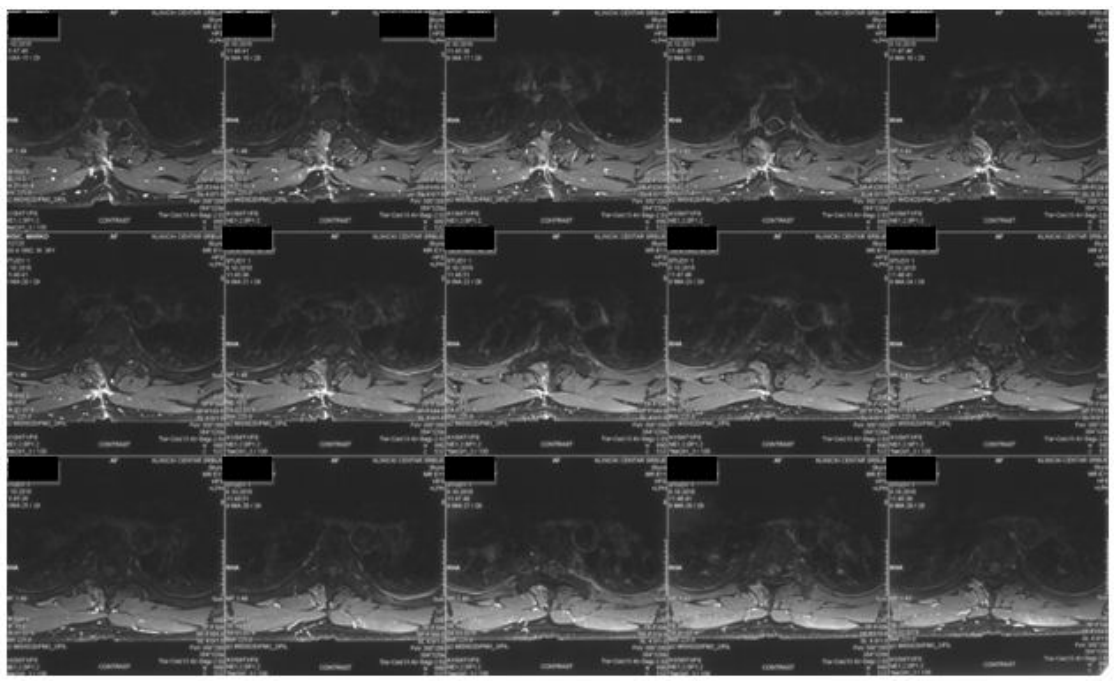

Figure 3 (postoperative MRI axial T1 with contrast)

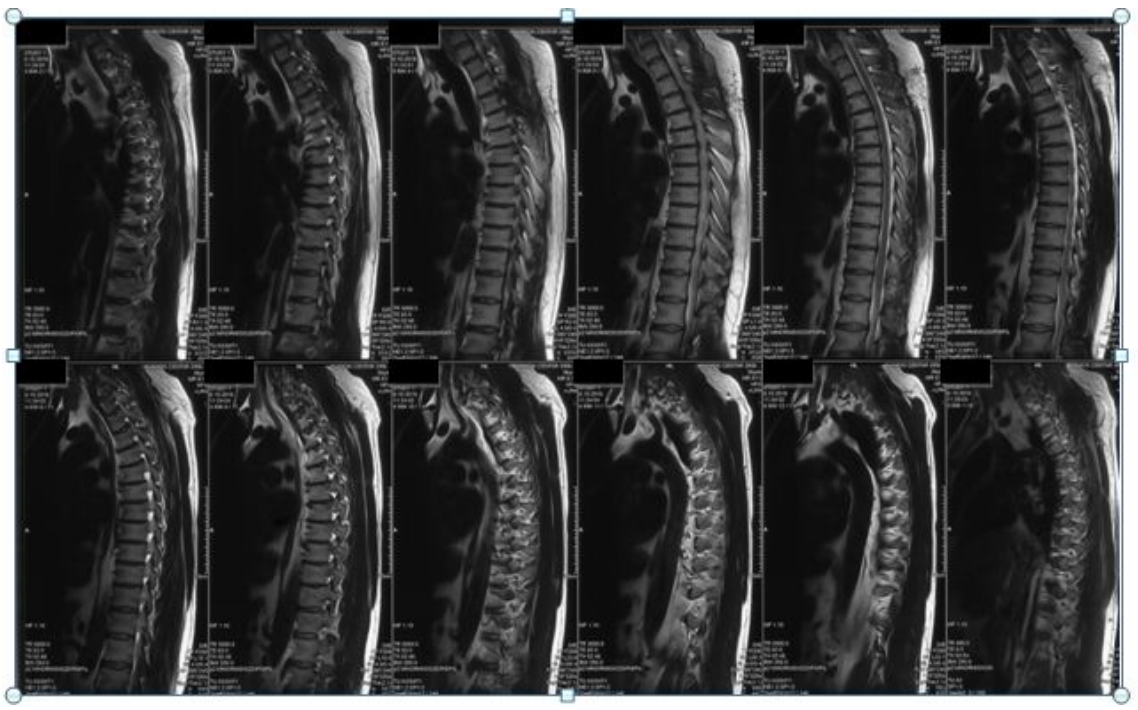

Figure 4 (postoperative MRI T2 sagital view)

Discussion:

The first description of Harlequin syndrome was in 1988 by Lance at al. ${ }^{1}$ They described five cases of adult patients with unilateral flushing and sweating with contralateral anhidrosis. In years that followed (1993) this phenomenon was described as a dysfunction of the pregangliotic and postganglioticcervical sympathetic nerve fibers and parasympathetic neurons of ciliary ganglion ${ }^{5}$.

The anatomy of sympathetic fibers innervating the face are made of a three- neuron chain pathway: first neurons originate in hypothalamus and synapse in the intermediolateral cell column of the upper thoracic spinal cord with preganglionic fibers (second neurons) - somewhere between Th1 - Th3 ${ }^{9}$. Preganglionic fibers leave the spinal cord at Th2 -Th3, synapsing with the postganglionic fibers (third neurons) in superior cervical ganglion. Then, postganglionic fibers leave cervical ganglion passing either along internal carotid 
artery to supply forehead, nose and eye, or along external carotid artery to supply the rest of the face. Preganglionic oculosympathetic neurons originate at the level of Th1.

In our case the lesion is at the level of inferior cervical ganglion (stellate ganglion) given the symptoms unilateral facial flushing and upper extremity and trunk, without Horner's syndrome. Harlequin sign in our case presented probably due to resection of sympathetic nerves while removing meningioma.

The PubMed database was searched online (PubMed, http:// pubmed.com). A search query using Harlequin syndrome revealed 129 published cases of which 23 was iatrogenic. (Table 1) Of 23 patients female sex was predominant $-15: 8$ ratio in which 8 were pediatric patients.

Most of the patients had undergone a thoracic surgery (8 patients), Intrathecal pump in 3 patients, total thyroidectomy and neck surgery (3 patients), five patients underwent spinal nerve block, and only two had neurosurgical procedure.

Conclusion:

Harlequin syndrome as a condition often frightens the patients since it happens after the operation, while they perform their usual activities. In most cases (about 80\%) it resolves by itself within few hours. The patient fear and anxiety can be calmed by explaining the benign nature of the condition. If the patient has long term sequelae and the symptoms aren't tolerable, a contralateral sympathectomy or stellate ganglion block are options for symptom relief ${ }^{32,33}$.

\begin{tabular}{|c|c|c|c|c|c|}
\hline & Authors & Age & Sex & Pathology & Procedure \\
\hline 1 & Kydes A. T. et al. ${ }^{13}$ & $2 \mathrm{y}$ & M & Paraspinal neuroganglioma & Thoracotomy Th2 \\
\hline 2 & Zinboonyahgoon N. et al. ${ }^{14}$ & $58 \mathrm{y}$ & $\mathrm{F}$ & Metastatic non small sell lung cancer & Intrathecal pump - \\
\hline 3 & Zinboonyahgoon N. et al. ${ }^{14}$ & $37 \mathrm{y}$ & $\mathrm{F}$ & Metastatic breast cancer & Intrathecal pump - \\
\hline 4 & Soto G.D. et Al. ${ }^{15}$ & $45 \mathrm{y}$ & $\mathrm{F}$ & Pituitary macroadenoma & Transsphenoidal en \\
\hline 5 & Jai N. Darvall et Al. ${ }^{16}$ & $26 \mathrm{~m}$ & M & Left side neck mass & Resection of the me \\
\hline 6 & Jeon Y.J. et al. ${ }^{17}$ & $6 y$ & M & Mass in posterior mediastinum extension to Th2-Th5 & Thoracotomy Th2- \\
\hline 7 & Lee D.H et $\mathrm{Al}^{18}$ & $11 y$ & M & Right side neck mass & Resection of the me \\
\hline 8 & Jung J.M. et al ${ }^{19}$ & $43 y$ & $\mathrm{~F}$ & Solitary pulmonary nodule & Endoscopic resectio \\
\hline 9 & Hussein N. et al ${ }^{20}$ & $58 \mathrm{y}$ & $\mathrm{F}$ & Squamocellular carcinoma of right upper lobe & Right lobectomy \\
\hline 10 & Lefevre A. et $\mathrm{al}^{21}$ & $10 \mathrm{y}$ & M & Thorasic epidural anesthesia & Nuss procedure \\
\hline 11 & Fringeli Y. et al. ${ }^{22}$ & $55 \mathrm{y}$ & $\mathrm{F}$ & disc herniation $\mathrm{C} 6-7$ & Anterior C6-7 disce \\
\hline 12 & Viswanath $\mathrm{O}$ et $\mathrm{al}^{23}$ & & $\mathrm{~F}$ & left lower lobe of the lung mass & Th3 - Th11 nerve b \\
\hline 13 & Irtan S. et $\mathrm{al}^{24}$ & $9 \mathrm{~m}$ & $\mathrm{~F}$ & Left stellate gangla neuroblastoma & Resection of the \\
\hline 14 & Nagasaka Y. et al. ${ }^{25}$ & $64 y$ & $\mathrm{~F}$ & breast adenocarcinoma & Paravertebral block \\
\hline 15 & Wagner R. et al. ${ }^{26}$ & $2 \mathrm{y}$ & $\mathrm{F}$ & tracheoesophageal fistula & Thoracoscopic oper \\
\hline 17 & Sullivan T. et. al. ${ }^{27}$ & / & $\mathrm{F}$ & breast cancer & erector spine plane \\
\hline 18 & Yamaguchi H. et al. ${ }^{28}$ & $1 \mathrm{y}$ & $\mathrm{M}$ & Esophageal atresia & Rightsided thorac \\
\hline 19 & Mohindraet al. ${ }^{29}$ & $84 y$ & $\mathrm{M}$ & left-sided neck lump / papillary thyroid carcinoma/ & total thyroidector \\
\hline 21 & Tyrell J.R.J. et al. ${ }^{30}$ & $76 y$ & M & lung adenocarcinoma & extra pleural bup \\
\hline 22 & Redondo J. M. et al. ${ }^{31}$ & $31 \mathrm{y}$ & $\mathrm{F}$ & epidural anesthesia in labor & Cesarean section \\
\hline 23 & Sribnik E.A. et al. ${ }^{32}$ & $42 \mathrm{y}$ & $\mathrm{F}$ & metastatic breast cancer & mastectomy and rig \\
\hline
\end{tabular}

Table (iatrogenic cases of Harlequin syndrome)

Data Availability Statement: All data are fully available without restriction

UNIVERSITY CLINICAL CENTER

OF SERBIA

11000 Belgrade; Pasterova St. No. 2, REPUBLIC OF SERBIAETHICS COMMITTEE11000 
Belgrade, Pasterova St. No. 2 +381 11366 2080, 264 4850, Fax: +381 113067180 Ref. o.: $175 / 6$ Date: 27.04.2021 Based on the provisions of the Republic of Serbia Healthcare Law („Official Gazette of the Republic of Serbia” no. 25/2019 ), Law on Patients' Rights („Official Gazette of the Republic of Serbia”, no. 45/13), Law on Personal Data Protection („OfficialGazette of the Republic of Serbia” no. 97/2008, 104/2009 and other laws), Law on health documentation and records in the field of health („Official Gazette of the Republic of Serbia" , no. 123/2014 , 106/2015 , 105/2017), acting in accordance with the provisions of the Rulebook of procedures for the Ethics Committee of the University Clinica l Center of Serbia no. $432 / 8$ from 28.02.2020, the Ethics Committee of the University Clinical Center of Serbia, in the composition, as follows: Prof. Andrija Bogdanovic MD PhD - Chairman, Prof. Brani slava Milenkovic MD, PhD, Prof. Branislava Ivanovic MD, PhD, Prof. Marina Svetel MD PhD, Dijana Sefer MD, Prof. Aleksandra Jotic MD, PhD, Prof. Aleksandra Peric-Popadic MD, PhD, Prof. Milos Korac MD, PhD, Prof. Aleksandar Stefanovic MD, PhD, Prof. Milan Latas MD, PhD and Docent Danijel Galun MD, PhD - all Specialists employed in the University Clinical Center of Serbia, ruling on request of Clinic for Neurosurgery of the University Clinical Center of Serbia on its $2^{\text {nd }}$ e-meeting, held on 27.04.2021, adopted the following DECISION It is granted publication of the paper/ case report called: Latrogenic Harlequin syndrome after thoracic spine surgery: a case report and literary review. Authors of the paper (case report) are: Jelena kostic MD, Zayed Abousabie MD, Mohamed Almezogi MD, Aleksandar Janicijevic MD and Prof. Goran Tasic MD, PhD. Expert collegiate of the Clinic for Neurosurgery of the University Clinical Center of Serbia gave the consent for publication of the case report. Paper would be published in the foreign medical journals. [Place of the stamp: round official seal] CHAIRMAN OF THE ETHICS COMMITTEE sgd. Professor Andrija Bogdanovic MD, PhD

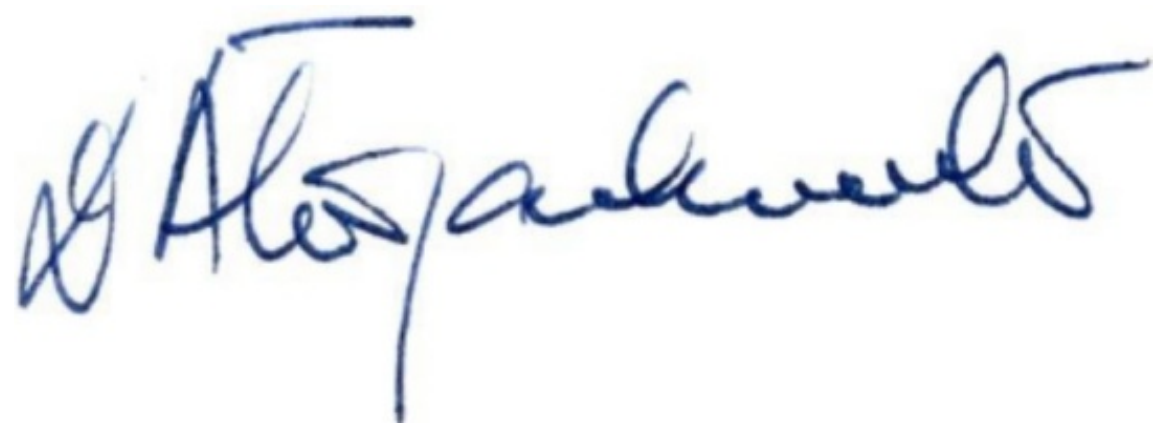

Reference:

1. Lance JW, Drummond PD, Gandevia SC, et al, 1988 Harlequin syndrome: the sudden onset of unilateral flushing and sweating. J NeurolNeurosurg Psychiatry 1: 635-642.

2. Vidal Esteban A, Natera-de Benito D, Martínez Sánchez D, RecheSainz A, Rodríguez Díaz MR, Alfaro Iznaola CM, et al. Congenital Harlequin syndrome as an isolated phenomenon: A case report and review of the literature. Eur J Paediatr Neurol. 2016;20:426-430.

3. Breunig J de A, Hartmann M, Freire CF, Almeida Jr HL. Harlequin syndrome in childhood - Case report. An Bras Dermatol. 2012;87:907-909.

4. Reeves AG, Posner JB. The ciliospinal response in man. Neurology 1969; 19:1145-52.

5. Pradeep PV, Benede AK, Harshita SS, Jayashree B, 2011 Harlequin syndrome in a case of toxic goitre: a rare association. Case Report Med pp 293076.

6. Algahtani H, Shirah B, Algahtani R and Alkahtani A. Idiopathic Harlequin syndrome manifesting during exer-cise: a case report and review of literature. Case Rep Med 2017; 2017: 5342593.

7. Burlacu CL and Buggy DJ. Coexisting Harlequin and Horner syndromes after high thoracic paravertebral anaes- thesia. Br J Anaesth 2005; 95: 822-824.

8. Drummond P. D., Lance J. W. Site of autonomic deficit in Harlequin syndrome: local autonomic failure affecting the arm and the face. Annals of Neurology . 1993;34(6):814-819. doi: 10.1002/ana.410340610.

9. Willaert WIM, Scheltinga MRM, Steenhuisen SF, Hiel JAP. Harlequin syndrome: two new cases and 
a management proposal.ActaNeurolBel. 2009; 109: 214-220.

10. Reeves AG, Posner JB. The ciliospinal response in man. Neurology 1969; 19:1145-52.

11. Sarikaya H. Georgiadis D, Baumgartner RW: Harlequin syndrome in spontaneous dissection of the cervical carotid artery. Neurology 71: 1459, 2008

12. Guilloton L., Demarquay G., Quesnel L., Charry De F., Drouet A., Zagnoli F.: Dysautonomic syndrome of the face with Harlequin sign and syndrome: three new cases and a review of the literature. Revue neurologique 169: 884-891, 2013

13. Ashley T Kydes, Ashley M Kelley, Samir R Pandya, Samuel M Barst: Postoperative Harlequin Syndrome: Case Report of a Rare but Clinically Striking Condition; A A Pract, 2018, 10(8):215-217.

14. NantthasornZinboonyahgoon, Suresh Srinivasan, SanjeetNarang: Harlequin Syndrome Following Implantation of Intrathecal Pumps: A Case Series, Neuromodulation 2015;18(8):772-5.

15. Gonzalo Díaz-Soto, Maria J Vaquerizo, CiroGarcía-Álvarez, Aurelia Villar-Bonet: Harlequin syndrome post-transsphenoidal pituitary macroadenoma surgery; Hormones (Athens) 2012;11(2):207-9.

16. Jai N Darvall, Adel W Morsi, Anthony Penington: Coexisting harlequin and Horner syndromes after paediatric neck dissection: a case report and a review of the literature; JPlastReconstAesthetSurg 2008;61(11):1382-4.

17. YeongJeongJeon, Jongbae Son, Jong Ho Cho: Harlequin Syndrome Following Resection of Mediastinal Ganglioneuroma; Korean J. ThoracCardiovascSurg 2017; 50(2): 130-132.

18. Dong Hoon Lee, MD, Jong Yuap Seong, MD, Tae Mi Yoon, MD, Joon Kyoo Lee, MD*, Sang Chul Lim, MD : Harlequin syndrome and Horner syndrome after neck schwannoma excision in a pediatric patient - A case report; Medicine (Baltimore) 2017;96(45):e8548.

19. Joon Min Jung, Mi Hye Lee, Chong Hyun Won, Sung Eun Chang, Mi Woo Lee, Jee Ho Choi, Kee Chan Moon : Iatrogenic Harlequin Syndrome: A New Case; Ann Dermatol 2015 ;27(1):101-2.

20. Hussein N, Haqzad Y, Lodhia J, Begum S, Cowen M: Harlequin syndrome following upper lobectomy.;Asian Cardiovasc Thorac Ann. 2018;26(3):234-235.

21. Ashley Lefevre, Gregory Schnepper: Development of Harlequin Syndrome following placement of thoracic epidural anesthesia in a pediatric patient undergoing Nuss procedure; Clin Case Rep 2017;5(9):1523-1525.

22. Yannick Fringeli, Andrea M Humm, AlexandreAnsorge, GianlucaMaestretti:Harlequin sign concomitspine ant with Horner syndrome after anterior cervical discectomy: a case of intrusion into the cervical sympathetic system; J Neurosurg2017;26(6):684-687.

23. Omar Viswanath, Jarrod Wilson, Frederick Hasty: Harlequin Syndrome Associated with Multilevel Intercostal Nerve Block; Anesthesiology 2016 Nov;125(5):1045.

24. Sabine Irtan , Anne Auvrignon: Harlequin Syndrome after Stellate Ganglia Neuroblastoma Resection; J Pediatr. 2016;176:215-215.e1.

25. Yasuko Nagasaka, Gunnar Wasner, Balram Sharma, Katharine Fleischmann: Harlequin Syndrome After Thoracic Paravertebral Block; A A Case Rep. 2016;6(3):48-51.

26. Richard Wagner, Martin Lacher, Andreas Merkenschlager, Moritz Markel: Harlequin Syndrome after Thoracoscopic Repair of a Child with Tracheoesophageal Fistula (TEF);European J PediatrSurg Rep 2019;7(1):e63-e65.

27. Timothy R. Sullivan, Pushpinder Kanda, Sylvian Gagne, IoanaCostache: Harlequin Syndrome Associated with Erector Spinae Plane Block; Anesthesiology, 2019 Sep;131(3):665.

28. Hiroshi Yamaguchi, Akiko Yokoi, KatsunoriKamimura, Yusuke Ishida, DaisakuToyoshima, Azusa Maruyama:Harlequin Syndrome; Indian J. Pediatr. 2018;85(8):700-701.

29. A Mohindra, M K Herd, N Roszkowski, I P Downie: Concurrent Horner's and Harlequin syndrome; Int J Oral Maxillofac Surg 2015;44(6):710-2.

30. J R J Tyrrell, P Trumpelmann, M H Chamberlain: Harlequin syndrome after extrapleural bupivacaine infusion; J Anaesth 2012;109(2):295-6.

31. Juan M. Redondo, Maria L. Martin, Maria D. Torrado, Maria J Rodriguez:Harlequin syndrome as a rare complication after epidural anesthesia in an obstetric patient Minerva Anestesiol 2018;84(4):524526 . 
32. Eric Anthony Sribnick, Nicholas M Boulis: Treatment of Harlequin syndrome by costotransversectomy and sympathectomy: case report; Neurosurgery 2011;69(1):E257-9.

33. Reddy H, Fatah S, Gulve A, Carmichael AJ. Novel management of harlequin syndrome with stellate ganglion block. Br J Dermatol. 2013;169:954-6. 